UDC 349.6

LBC 67.72

\title{
SOME ISSUES OF APPLYING ATTORNEY'S SUBMISSION AS A REMEDY TO SUPPRESS VIOLATIONS OF THE ENVIRONMENTAL LEGISLATION
}

\author{
Sergey V. Filipenko \\ Saratov Region Attorney's Office, Saratov, Russian Federation
}

Introduction: the supervision of the observance of the environmental legislation is one of the priorities of the Attorney's Office which solves the problems of suppression of violations and their prevention in future. The submission on correcting violations of the law is one of the most effective remedies of the attorney's response. However, its application is accompanied by a number of problematic issues, by virtue whereof the author sets the goal of studying and solving one of them. Methods: the methodological framework of the research is a set of methods of scientific knowledge, among which the main are the methods of systematicity, analysis and the comparative law one. Results: proved in the work the author's position is based on the legislation and opinions of the competent scientific community on the grounds for making the attorney's submission. Conclusions: as a result of the study the author identified the grounds for bringing into the federal legislation a rule on the extension of grounds for applying the attorney's submission on the violations of the bylaws along with the violations of the law.

Key words: environmental legislation, ecology, attorney, submission on suppressing violations of the law, an act of attorney's response, demand, law, bylaw, legal cause.

УДК 349.6

ББК 67.72

\section{НЕКОТОРЫЕ ВОПРОСЫ ПРИМЕНЕНИЯ ПРЕДСТАВЛЕНИЯ ПРОКУРОРА КАК СРЕДСТВА ПРЕСЕЧЕНИЯ НАРУШЕНИЙ ПРИРОДООХРАННОГО ЗАКОНОДАТЕЛЬСТВА}

\author{
Сергей Владимирович Филипенко \\ Прокуратура Саратовской области, г. Саратов, Российская Федерация
}

Введение: надзор за соблюдением природоохранного законодательства является одним из приоритетных направлений деятельности прокуратуры, в ходе которой решаются задачи пресечения нарушений и предотвращения их совершения в будущем. Представление об устранении нарушений закона относится к числу наиболее эффективных средств прокурорского реагирования. Вместе с тем его применение сопровождается рядом проблемных вопросов, в связи с чем автором поставлена цель изучения и решения одного из них. Методы: методологическую основу данного исследования составляет совокупность методов научного познания, среди которых основное место занимают методы системности, анализа и сравнительно-правовой. Результаты: обоснованная в работе авторская позиция опирается на законодательство, мнения компетентной научной среды по вопросу оснований внесения прокурором представления. Выводы: в результате исследования обосновано внесение в федеральное законодательство нормы о расширении оснований для применения представления при нарушениях подзаконных актов наряду с нарушениями закона.

Ключевые слова: природоохранное законодательство, экология, прокурор, представление об устранении нарушений закона, акт прокурорского реагирования, требование, закон, подзаконный акт, правовое основание. 


\section{Введение}

Экологическая безопасность является одним из основных условий достойного существования и успешного развития общества. Об исключительности права на благоприятную окружающую среду свидетельствует его закрепление в ст. 42 Конституции России. Реальность обеспечения данного права в первую очередь зависит от согласованных действий различных органов государственной власти.

Важнейшую роль в системе указанных мероприятий играет надзорная деятельность прокуратуры. Так, в 2016 г. в Саратовской области за указанный период установлено 2233 нарушения. Для устранения противоправных деяний и предотвращения их совершения надзорные органы применяют комплекс мер пресекательного, карательного и профилактического характера.

Наиболее распространенным актом прокурорского реагирования по числу случаев использования в данной сфере является представление об устранении нарушений закона (далее представление). За 2016 г. в Саратовской области прокуроры 869 раз ${ }^{1}$ использовали полномочия по внесению представлений об устранении нарушений законодательства по охране окружающей среды и природопользования.

Результатом данной практики явилось снижение числа нарушений закона, выявленных органами прокуратуры Саратовской области за 2016 г. на 31 \% в сравнении с 2015 годом.

Таким образом, внесение представления является одним из действенных способов укрепления законности в области охраны окружающей среды и природопользования.

\section{Основания применения представления}

Полномочие по применению указанного акта прокурорского реагирования предусмотрено ст. 24, 26 Федерального закона от 17 января 1992 г. № 2202-1 Федерального закона «О прокуратуре Российской Федерации» [12]. Из анализа данных норм можно сделать вывод о том, что представление обладает всеми признаками акта применения права: используется по результатам разрешения определенной правовой ситуации, заключает в себе вла- стное веление, издается в определенной форме $[2$, с. $254-255 ; 5$, с. $164 ; 6$, с. $378-380]$.

Основанием для внесения представления является нарушение закона. Правовые последствия - возникновение у адресата представления следующих обязанностей: а) рассмотреть его; б) принять конкретные меры по устранению допущенных нарушений закона, причин и условий, им способствующих; в) проинформировать прокурора; г) нести ответственность в случае неисполнения требований прокурора, объективированных в указанном акте.

Применение указанного акта реагирования нередко сопровождает ряд проблемных вопросов. Один из них - ограниченность правовых оснований для его внесения, которыми могут служить лишь факты нарушений закона. Вместе с тем органы, наделенные властными полномочиями, вправе издавать нормативные акты в пределах своей компетенции, необходимость которых прямо не установлена в законе. Среди подобных актов следует отметить: указы Президента РФ «О мерах по обеспечению охраны морских биологических ресурсов и государственного контроля в этой сфере» [10], «О некоторых мерах по повышению энергетической и экологической эффективности российской экономики» [11], постановления Правительства РФ «О Министерстве природных ресурсов и экологии Российской Федерации» [8], «О рекультивации земель, снятии, сохранении и рациональном использовании плодородного слоя почвы» [9] и другие.

Издание данных нормативных актов прямо не предусмотрено ни одним законом. При этом сложно переоценить важность вопросов, которые регулируются ими. Неисполнение требований указанных актов ставит под угрозу нормальное состояние природных ресурсов, что может неблагоприятно отразиться на экологической обстановке в стране.

В случае их нарушения прокурор лишен права внести представление, так как данные нормативные акты не являются законами и не изданы по прямому указанию, содержащемуся в каком-либо законе.

Вместе с тем одной из целей деятельности прокуратуры, как следует из ст. 1 Ф3 «О прокуратуре Российской Федерации», является укреплениезаконности. Понятия законности и близкого ему правопорядка связаны с соблюдением 
Представление прокурора как средство пресечения нарушений природоохранного законодательства

действующих правовых норм, содержащихся как в законах, так и в подзаконных актах [1, с. 329$330,335-336 ; 4$, с. 302-307; 7, с. 116-118].

Внесение представления является для прокурора универсальным способом требовать от уполномоченного лица или органа прекратить действия, нарушающие действующее законодательство [3, с. 165]. Иные меры реагирования пресекательного характера (внесение протеста, требования об изменении нормативного правового акта) могут применяться лишь в отношении противоправных деяний, объективированных в виде правовых актов.

В связи с данным пробелом правового регулирования прокурор лишен возможности в полной мере выполнить задачи, установленные для него законом, по причине отсутствия возможности требовать от поднадзорных органов и должностных лиц прекращения нарушений подзаконных нормативных актов.

Учитывая вышеизложенное, имеется объективная необходимость дополнения ст. 1 , 22, 24, 28 Ф3 «О прокуратуре» положением о возможности внесения прокурором представления в связи с нарушениями не только законов, но и других нормативных правовых актов.

\section{Выводы}

Таким образом, внесение представления является одной из эффективных мер по пресечению и профилактике нарушений природоохранного законодательства.

Однако повышению результативности использования полномочия по внесению представлений должно способствовать расширение круга его оснований путем дополнения указанием на подзаконные нормативные акты.

\section{ПРИМЕЧАНИЕ}

${ }^{1}$ Номенклатурное дело статистического отчета «Надзор за исполнением законов, соблюдением прав и свобод человека и гражданина» прокуратуры Саратовской области.

\section{СПИСОК ЛИТЕРАТУРЫ}

1. Абдулаев, М. И. Теория государства и права / М. И. Абдулаев. - М. : Финансовый контроль, 2004. -410 c.
2. Алексеев, С. С. Теория права / С. С. Алексеев. - М. : БЕК, 1995. -320 с.

3. Винокуров, Ю. Е. Прокурорский надзор / Ю. Е. Винокуров. - М. : Высшее образование, 2005. $-460 \mathrm{c}$.

4. Лисюткин, А. Б. Теория государства и права / А. Б. Лисюткин. - М. : Юристь, 2001. - 776 с.

5. Матузов, Н. И. Теория государства и права / Н. И. Матузов, А. В. Малько. - М. : Юристь, 2004. $512 \mathrm{c}$.

6. Мелехин, А. В. Теория государства и права / А. В. Мелехин. - М. : Маркет ДС, 2007. - 640 с.

7. Попов, В. В. Некоторые методологические проблемы формулирования предметной области понятий «законность» и «правопорядок» / В. В. Попов // Вестник Волгоградского государственного университета. Серия 5, Юриспруденция. - 2016. T. 15, № 4 (33). - C. 115-119. - DOI: https://doi.org/ 10.15688/jvolsu5. 2016.4.17.

8. Постановление Правительства РФ «О Министерстве природных ресурсов и экологии Российской Федерации» от 29 мая 2008 г. № 404 // Собрание законодательства РФ. - 2008. - 2 июня. № 22. - Ст. 2581.

9. Постановление Правительства РФ «О рекультивации земель, снятии, сохранении и рациональном использовании плодородного слоя почвы» от 23 февр. 1994 г. № 140 // Собрание актов Президента и Правительства РФ. - 1994. - № 10. - Ст. 779.

10. Указ Президента РФ «О мерах по обеспечению охраны морских биологических ресурсов и государственного контроля в этой сфере» от 29 авг. 1997 г. № 950 // Собрание законодательства РФ. 1997. - 1 сент. - № 35. - Ст. 4060.

11. Указ Президента РФ «О некоторых мерах по повышению энергетической и экологической эффективности российской экономики» от 4 июня 2008 г. № 889 // Собрание законодательства РФ. 2008. - 9 июня. - № 23. - Ст. 2672.

12. Федеральный закон «О прокуратуре Российской Федерации» от 17 янв. 1992 г. № 2202-I // Российская газета. - 1992. - 18 февр. (№ 39).

\section{REFERENCES}

1. Abdulaev M.I. Teoriya gosudarstva i prava [Theory of State and Law]. Moscow, Finansovyy kontrol Publ., 2004. 410 p.

2. Alekseev S.S. Teoriya prava [Theory of Law]. Moscow, BEK Publ., 1995. 320 p.

3. Vinokurov Yu.E. Prokurorskiy nadzor [Attorney's Supervision]. Moscow, Vysshee obrazovanie Publ., 2005. 460 p.

4. Lisyutkin A.B. Teoriya gosudarstva i prava [TheoryofState andLaw]. Moscow, Yurist Publ., 2001.776 p. 
5. Matuzov N.I., Malko A.V. Teoriya gosudarstva i prava [Theory of State and Law]. Moscow, Yurist Publ., 2004. 512 p.

6. Melekhin A.V. Teoriya gosudarstva i prava [Theory of State and Law]. Moscow, Market DS Publ., 2007, pp. 378-380.

7. Popov V.V. Nekotorye metodologicheskie problemy formulirovaniya predmetnoy oblasti ponyatiy «zakonnost» i «pravoporyadok» [Some Methodological Problems of Formulating the Subject Field of the Concepts "Legality" and "Legal Order"]. Vestnik Volgogradskogo gosudarstvennogo universiteta. Seriya 5, Yurisprudentsiya [Science Journal of Volgograd State University. Jurisprudence], 2016, vol. 15, no. 4 (33), pp. 115-119. DOI: https://doi. org/10.15688/jvolsu5.2016.4.17.

8. Postanovlenie Pravitelstva $\mathrm{RF} « \mathrm{O}$ Ministerstve prirodnykh resursov i ekologii Rossiyskoy Federatsii» ot 29 maya 2008 g. № 404 [The Decree of the Government of the Russian Federation "On the Ministry of Natural Resources and Ecology of the Russian Federation» of May 29, 2008 no. 404]. Sobranie zakonodatelstva RF [Collected Legislation of the Russian Federation], 2008, June 2 (no. 22), art. 2581

9. Postanovlenie Pravitelstva $\mathrm{RF} « \mathrm{O}$ rekultivatsii zemel, snyatii, sokhranenii i ratsionalnom ispolzovanii plodorodnogo sloya pochvy» ot 23 fevr. 1994 g. № 140 [The Decree of the Government of the Russian Federation
"On Land Reclamation, Removal, Preservation and Rational Use of Topsoil” of February 23, 1994 no. 140]. Sobranie aktov Prezidenta i Pravitelstva RF [Collected Acts of the President and the Government of the Russian Federation], 1994, no. 10, art. 779.

10. Ukaz Prezidenta $\mathrm{RF} « \mathrm{O}$ merakh po obespecheniyu okhrany morskikh biologicheskikh resursov i gosudarstvennogo kontrolya v etoy sfere» ot 29 avg. 1997 g. № 950 [The Decree of the President of the Russian Federation "On Measures to Ensure the Protection of Marine Biological Resources and State Control in this Sphere" of August 29, 1997 no. 950]. Sobranie zakonodatelstva RF [Collected Legislation of the Russian Federation], 1997, September 1 (no. 35), art. 4060.

11. Ukaz Prezidenta RF «O nekotorykh merakh po povysheniyu energeticheskoy i ekologicheskoy effektivnosti rossiyskoy ekonomiki» ot 4 iyunya $2008 \mathrm{~g}$. № 889 [The Decree of the President of the Russian Federation "On Some Measures to Improve the Energy and Environmental Efficiency of the Russian Economy" of June 4, 2008 no. 889]. Sobranie zakonodatelstva $R F$ [Collected Legislation of the Russian Federation], 2008, June 9 (no. 23), art. 2672.

12. Federalnyy zakon $« \mathrm{O}$ prokurature Rossiyskoy Federatsii» ot 17 yanv. 1992 g. № 2202-I [The Federal Law “On Attorney's Office of the Russian Federation" of January 17, 1992 no. 2202-I]. Rossiyskaya gazeta, 1992, February 18 (no. 39).

\section{Information about the Author}

Sergey V. Filipenko, the Saratov Region Attorney, E.F. Grigoryeva St., 33/39, 410002 Saratov, RussianFederation, filipenko83@yandex.ru.

\section{Информация об авторе}

Сергей Владимирович Филипенко, прокурор Саратовской области, ул. им. Е.Ф. Григорьева, 33/39, 410002 г. Саратов, Российская Федерация, filipenko83@yandex.ru. 